\title{
Multiple Extramedullary Plasmacytomas Of Diaphragm And Chest Wall
}

\author{
M Mathew, S Ray
}

\section{Citation}

M Mathew, S Ray. Multiple Extramedullary Plasmacytomas Of Diaphragm And Chest Wall. The Internet Journal of Pulmonary Medicine. 2008 Volume 10 Number 2.

\section{DOI: $10.5580 / 1439$}

\begin{abstract}
Extramedullary plasmacytoma accounts for $3 \%$ of all plasma cell neoplasms. These tumors have been documented in the gastrointestinal tract, thyroid, salivary glands, lungs, lymphnode and skin. However, multiple plasmacytoma involving the diaphragm and chest wall is rare. We report a case in a 45 year old male who presented with right posterio-lateral, painless, chest wall tumor involving the 9th rib and infiltrating the parietal pleura. 3 additional nodules were noted in the diaphragm. Microscopy revealed a tumor composed of abnormal plasma cells which were positive for CD 79a, CD 138 \& MUM 1 antibodies. The tumor cells also showed monotypic immunoreactivity for lambda light chains.
\end{abstract}

\section{INTRODUCTION}

Extramedullary plasmacytoma (EMP) is a rare entity, classified under the category of non-Hodgkin lymphoma. According the review of literature in a study done by Alexiou et al1, approximately $43 \%$ of EMP occur in the upper aerodigestive tract followed by the nasopharyngeal region. However, diaphragm and chest wall plasmacytomas, especially multiple tumors occurring synchronously has not been documented in the literature.

\section{CASE REPORT}

A 45 year old male presented with a massive painless lump in the right posterio-lateral chest wall of one month duration. CT scan revealed a primary chest wall tumor arising in relation to the posterior end of the right 9 th rib with destruction. Extensive tumor infiltration involving the posterior wall of the right pleural cavity was seen. In addition to this, he had right pleural effusion and enlarged retrocaval nodes. He underwent thorocotomy.

\section{INVESTIGATIONS}

The patient's hemoglobin was $12.3 \mathrm{~g} / \mathrm{dl}$ and ESR was $82 \mathrm{~mm}$ at the end of one hour. Bone marrow examination revealed no evidence of myeloma. Urine 24 hour protein was normal and urine Bence Jones protein was negative. Protein electrophoresis revealed a faint band between $\square$ and $\square$ region $\mathrm{M}$ band. The pleural fluid showed abnormal plasma cells.
Serum calcium, renal functions and skeletal survey were normal.

\section{PATHOLOGICAL FINDINGS}

The resected specimen showed a large tumor measuring 17.5 $\mathrm{x} 13.5 \mathrm{cms}$ and weighing $850 \mathrm{gms}$ along with attached ribs and muscle. Cut section revealed a grey-white lobulated, homogenous tumor. 3 tumor nodules from the diaphragm showed grey-brown homogenous areas. Histopathology of the mass and tumor nodules showed a diffuse infiltrate of plasma cells with eosinophilic cytoplasm, eccentric nuclei and clumped chromatin, infiltrating the muscle planes (Fig 1). The tumor cells were Vimentin, CD 79a, CD 138 and MUM-1 antibodies positive. Monotypic immmunoreactivity for lambda light chains was also seen. These cells were Kappa, LCA, CD 20, EMA, S-100, CK and Desmin negative. 


\section{Figure 1}
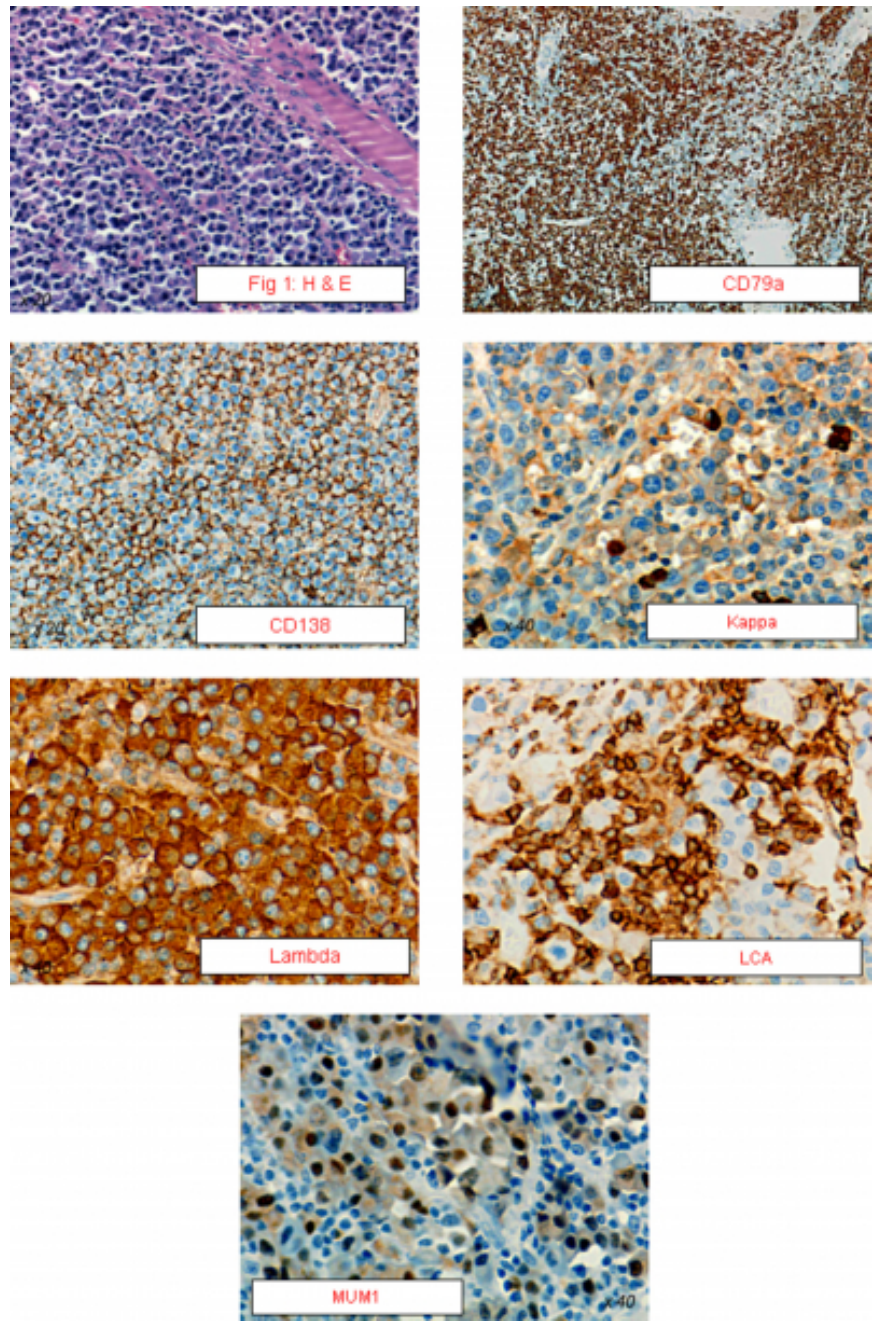

\section{DISCUSSION}

EMP's represents a distinct group of neoplasms both biologically and prognostically $y_{2}$. Few cases of EMP involving the pleura have been described, but without the involvement of the diaphragm1. Chest wall plasmacytoma with synchronous, multiple extramedullary plasmacytomas of the diaphragm and abnormal plasma cells in the pleural fluid has not been documented in the literature. Multiple extramedullary lesions and myelomatous pleural effusion and ascites are usually seen as a terminal event in solitary plasmacytomas $_{3}$. In our case, this was the initial presentation.

This tumor was CD 79a, CD 138 and MUM-1 positive, which confirmed the plasmacytic nature of the tumor. The abnormal plasma cells showed monotypic immunoreactivity for $\square$ light chain immunoglobulin. They were also vimentin positive which is seen in $70 \%$ of plasmacytomas ${ }_{4}$.

Extrarenal rhabdoid tumors and mesotheliomas can mimick plasmacytomas and this was eliminated with help of EMA, $\mathrm{CK}$ and Desmin antibodies. Non Hodgin lymphomas with plasmacytic differentiation was ruled out by a negative LCA and CD 20 antibodies. To the best of our knowledge, synchronous multiple plasmacytomas involving the chest wall and diaphragm with abnormal plasma cells in the pleural effusion has not been documented in the literature.

\section{ACKNOWLEDGEMENTS}

We wish to thank Dr R Pathmanathan, Senior consultant Pathologist, Subang Jaya Medical Centre, Malaysia for his help in immunohistochemistry staining of slides.

\section{References}

1. Alexiou C, Kau RJ, Dietzfelbinger H, Kremer M, Spieß JC, Schratzenstaller B et al.

Extramedullary plasmacytoma. Tumor occurrence and therapeutic concepts. Cancer.

1999; 85(11): 2305-2313.

2. Frizzera G. Castleman's disease and related disorders. Semin Diagn Pathol. 1988;5:

346-364.

3. Matsumoto A, Nagata K, Hamaguchi H, Taki K. Solitary bone plasmacytoma

terminally developed myeloma with multiple extramedullary lesions and myelomatous

pleural effusion and ascites. Int J Hematol.1993; Dec; 59(1): 59-65.

4. Bayer G, Ilene B, Schwartz, Mary R, Lin P, Smoller et al. CD117 but not lysozyme, is

positive in cutaneous plasmacytoma. Arch Pathol Lab

Medicine. 2003; 127(12):1596-

1596. 


\section{Author Information}

Mary Mathew, M.D.

Associate Professor, Department of Pathology, Kasturba Medical College

Satadru Ray, M.Ch.

Professor, Department of Surgical Oncology, Kasturba Medical College 